\title{
Morale in the English mental health workforce: questionnaire survey ${ }^{\dagger}$
}

Sonia Johnson, David P. J. Osborn, Ricardo Araya, Elizabeth Wearn, Moli Paul, Mai Stafford, Nigel Wellman, Fiona Nolan, Helen Killaspy, Brynmor Lloyd-Evans, Emma Anderson and Stephen J. Wood

\section{Background}

High-quality evidence on morale in the mental health workforce is lacking.

\section{Aims}

To describe staff well-being and satisfaction in a multicentre UK National Health Service (NHS) sample and explore associated factors.

\section{Method}

A questionnaire-based survey $(n=2258)$ was conducted in 100 wards and 36 community teams in England. Measures included a set of frequently used indicators of staff morale, and measures of perceived job characteristics based on Karasek's demand-control-support model.

\section{Results}

Staff well-being and job satisfaction were fairly good on most indicators, but emotional exhaustion was high among acute general ward and community mental health team (CMHT) staff and among social workers. Most morale indicators were moderately but significantly intercorrelated. Principal components analysis yielded two components, one appearing to reflect emotional strain, the other positive engagement with work. In multilevel regression analyses factors associated with greater emotional strain included working in a CMHT or psychiatric intensive care unit (PICU), high job demands, low autonomy, limited support from managers and colleagues, age under 45 years and junior grade. Greater positive engagement was associated with high job demands, autonomy and support from managers and colleagues, Black or Asian ethnic group, being a psychiatrist or service manager and shorter length of service.

\section{Conclusions}

Potential foci for interventions to increase morale include CMHTS, PICUs and general acute wards. The explanatory value of the demand-support-control model was confirmed, but job characteristics did not fully explain differences in morale indicators across service types and professions.

\section{Declaration of interest}

None.
The morale of the mental health workforce is important in several ways. First, this large workforce is exposed to substantial stresses and, at times, threats; ${ }^{1}$ ensuring staff well-being is thus a key challenge for employers. Second, high levels of staff sickness in the UK National Health Service (NHS) result in a large economic burden on the nation. ${ }^{2}$ Third, there is some evidence suggesting links between health staff well-being and patient experiences and outcomes. ${ }^{2}$ Finally, staff attitudes are a key factor facilitating or impeding implementation of new service initiatives. ${ }^{3}$ Implementation is particularly relevant to psychiatric in-patient care settings (a central focus of our study), as wards in the UK have been criticised for being threatening and unsafe environments in which therapeutic relationships are impoverished and treatment limited. This has resulted in a series of initiatives aimed at service improvement, which are unlikely to succeed unless a skilled and motivated workforce is recruited and retained. Despite its importance, research into staff morale remains limited, with a lack of large multisite studies that encompass all the main mental health professions and include subspecialties other than services for adults of working age. ${ }^{4,5}$ Our study aimed to address this need for large-scale evidence on morale in the mental health workforce. Like previous authors, ${ }^{6}$ we use morale as a general term encompassing the main aspects of work-related well-being and satisfaction and engagement with work. Specific objectives were:

(a) to describe staff well-being and satisfaction in a large multicentre sample, identifying whether there are subspecialties or professions in which morale problems are especially acutely felt or, conversely, morale levels are exemplary;

†See editorial, pp. 178-179, this issue. (b) to investigate the interrelationships of the measures of wellbeing and satisfaction used, and whether a smaller number of higher-order components can be derived from them;

(c) to explore how far variations in morale between settings and professions may be accounted for by job characteristics.

\section{Method}

Nineteen mental health trusts in England, each delivering a broad range of mental health services to a catchment area, were the study setting, drawn from the regions surrounding the four main participating universities: University College London and the universities of Warwick, Sheffield and Bristol. Area demographic and geographical characteristics varied widely.

\section{Sample and procedures}

The in-patient care sample was recruited on 100 wards. Half were acute general wards serving adults of working age resident within a specific catchment area; the remainder were divided between wards providing care for older people, rehabilitation wards (providing longer-term but time-limited care for severely ill people with major difficulties functioning in the community), forensic wards (caring for mentally ill offenders usually referred by the criminal justice system), child and adolescent mental health wards (for those under 18 years old) and psychiatric intensive care units (PICUs) (for patients too difficult to manage on a general ward). Eighteen community mental health teams (CMHTs) and 18 crisis resolution teams (CRTs) (providing rapid assessment and short-term intensive home treatment in a crisis) formed the community sample. 
Researchers approached all frontline clinical staff in the participating teams and their immediate managers, and invited them to complete our questionnaire. Assurances of confidentiality were provided and reminders and tokens of gratitude such as fruit and biscuits distributed. Multicentre ethical approval was obtained. Data collection commenced in late 2007 and was concluded in 2009.

\section{Measures}

Morale

Staff well-being and attitudes to work were assessed with the following five measures. First, burnout was rated with the Maslach Burnout Inventory, which yields three dimensions of burnout: emotional exhaustion, assessing the extent to which participants feel overburdened by their work; cynicism (a clearer description of this subscale than the original designation of 'depersonalisation"7), assessing how far they feel emotionally hardened and indifferent to patients; and personal accomplishment, measuring whether they feel they can work with patients effectively. ${ }^{8}$ The second measure was the Job-related Affective Well-being Scale, which in the version used generates two partially independent subscales: ${ }^{9}$ on the anxiety-contentment scale high scores represent predominance of contentment over anxiety and low scores the reverse, whereas on the depression- enthusiasm scale enthusiasm predominates at high scores and depression at low scores. Third, to assess job satisfaction we used a combination of items from the 2004 Workplace Employment Relations Survey and the NHS Staff Survey to cover the aspects of satisfaction that we wished to include; ${ }^{10,11}$ this generated several satisfaction subscores (see online Table DS2). Fourth, overall psychological health was rated with the 12-item version of the General Health Questionnaire (GHQ-12), ${ }^{12}$ covering depression, anxiety, suicidal ideas, happiness and sleep disturbance; using the Likert version each item is scored from 0 to 3 , and a total score of 12 or more out of 36 is the threshold for 'caseness', indicating potential morbidity. Finally, the Job Involvement Scale, which defines the degree of an individual's psychological identification with their work, was used as an indicator of motivation; ${ }^{13}$ we used a five-item measure. ${ }^{14}$

\section{Demographic and occupational details}

Structured questions elicited the participants' sociodemographic details and profession, length of service in mental health services and on their current ward, and seniority.

\section{Job characteristics}

Perceived job characteristics measured in the study originated from Karasek's 'demand-control' model of work-related strain, ${ }^{15}$ subsequently extended to include 'support.' ${ }^{16}$ Central to occupational psychology for the past two decades, this model has been widely replicated, although not prior to our study in a multidisciplinary sample of mental health staff. ${ }^{17}$ Job strain is conceptualised as resulting from the triad of high demands, low decisional latitude (autonomy) and low support. Good evidence also supports an extension of this - the idea that a combination of high demands, high autonomy and high support results in good motivation and job satisfaction. ${ }^{18}$ We measured demands and control using questions developed by Haynes et al for health staff, all rated on a five-point scale. ${ }^{19}$ Seven items related to the extent of demands made by jobs, including whether these exceeded available time and resources, conflicted with one another or made it impossible to follow best practice. Five items related to control: how much autonomy respondents had in deciding how to do their work. Three items in the same format measured support (including willingness to listen and helpfulness) from immediate managers, and four items measured support from colleagues.

\section{Statistical analysis}

We first estimated unadjusted mean morale indicators by service type and profession and tested for differences using analysis of variance. We originally planned to test the hypothesis that in-patient unit staff would have worse morale than those working in the community; this was not pursued, because descriptive statistics revealed large differences between hospital specialties. To ascertain relationships between indicators of morale we examined pairwise Pearson's correlations between all the subscales listed above. We then used principal components analysis to explore whether we could obtain plausible components onto which several indicators loaded to be used in further analyses. We then examined the associations between the components of staff morale and service type and profession, adjusted for other demographic and occupational variables. Mixed effects multilevel regression was used so that we could simultaneously model effects at both individual and service level, taking account of the non-independence of observations at each level. ${ }^{20}$ Multilevel models were then derived with each of the morale components as dependent variables: individuals were nested within services. Initially, profession and service type were included along with the demographic and job-related variables shown in Table 1. We then added job demands, support and control variables to the multilevel models obtained, assessing how far significant relationships between morale and service type and profession persisted with these variables included.

Less than $5 \%$ of the data were missing (between 13 and 144 cases per variable), but exclusion of all cases with missing data would have substantially reduced the sample. We therefore used multiple imputation, which fills in missing values based on values of other variables and a 'missing at random' assumption. Multiple imputation acknowledges uncertainty about the missing values by creating several imputed data-sets, in this case five following standard guidance that the number of imputed data-sets should exceed the overall proportion of missing data. ${ }^{21}$ The ice command in Stata version 10 for Windows was used to generate imputed data-sets and the mim commands to combine them in our multilevel regression analyses. ${ }^{22}$

\section{Results}

One hundred wards in 19 mental health trusts provided the in-patient staff sample: 50 acute general wards, 10 child and adolescent mental health service (CAMHS), 9 rehabilitation, 9 older people's, 12 forensic and 10 PICU wards. In the community we recruited 18 CMHTs and 18 CRTs. A total of 3545 questionnaires were distributed, of which 2258 valid responses were returned, a $64 \%$ response rate. At trust level the response rate varied from $52 \%$ to $72 \%$, median $60 \%$. Ward response rates ranged between $22 \%$ and $100 \%$, median $62 \%$.

Just over a third of respondents were men, three-quarters were from a White ethnic background and the mean age was 40.7 years (Table 1). Around half the participants were nurses and just over a quarter were nursing assistants, healthcare assistants or others without a relevant professional qualification. All other main mental health professions were represented in smaller groups. Five per cent were ward or community team managers, subsequently referred to as service managers. Temporary staff who had worked on the ward in a locum, bank or agency capacity for at least a month were encouraged to participate, but constituted only $2 \%$ 


\section{Table 1 Sample characteristics $(n=2258)^{\mathrm{a}}$}

\begin{tabular}{|c|c|}
\hline \multicolumn{2}{|l|}{ Service type, $n(\%)$} \\
\hline Acute general ward & 721 (35) \\
\hline CAMHS & $189(9)$ \\
\hline Forensic ward & 219 (11) \\
\hline MHCOP ward & $157(8)$ \\
\hline Rehabilitation ward & $137(7)$ \\
\hline PICU & $148(7)$ \\
\hline СMHT & 258 (13) \\
\hline CRT & $216(11)$ \\
\hline \multicolumn{2}{|l|}{ Professional group, $n(\%)$} \\
\hline Nurses & $1054(47)$ \\
\hline Doctors & $135(6)$ \\
\hline Psychologists & $44(2)$ \\
\hline Occupational therapists & $82(4)$ \\
\hline Nursing assistant/support worker/others without & \\
\hline professional qualifications & $640(29)$ \\
\hline Social workers & $86(4)$ \\
\hline Ward managers and team leaders (service managers) & $111(5)$ \\
\hline Other occupations & $93(4)$ \\
\hline \multicolumn{2}{|l|}{ Gender, $n$ (\%) } \\
\hline Men & $803(36)$ \\
\hline Women & $1421(64)$ \\
\hline \multicolumn{2}{|l|}{ Ethnic group, $n(\%)^{b}$} \\
\hline White & $1606(75)$ \\
\hline Black African, Caribbean or British & $329(15)$ \\
\hline Asian & $177(8)$ \\
\hline Other or mixed & $30(1)$ \\
\hline Age, years: mean (s.d.) & $40.7(10.4)$ \\
\hline \multicolumn{2}{|l|}{ Marital status, $n(\%)$} \\
\hline Single & $502(23)$ \\
\hline Married/cohabiting & $1463(67)$ \\
\hline Divorced/widowed/separated & $234(11)$ \\
\hline \multicolumn{2}{|l|}{ Place of birth, $n(\%)$} \\
\hline Born in the UK & $1664(76)$ \\
\hline \multicolumn{2}{|l|}{ Whether has any dependants (as parent or carer), $n$ (\%) } \\
\hline Has dependants & 1066 (49) \\
\hline \multicolumn{2}{|l|}{ Whether at senior grade, $n$ (\%) } \\
\hline $\begin{array}{l}\text { Agenda for Change Band } 7 \text { pay scale or above, } \\
\text { or consultant psychiatrist }\end{array}$ & $251(12)$ \\
\hline \multicolumn{2}{|l|}{ Whether working on a locum basis, $n$ (\%) } \\
\hline On a short-term (locum, bank or agency) contract & $52(2)$ \\
\hline \multicolumn{2}{|l|}{$\begin{array}{l}\text { Tenure (time working on current ward or in current } \\
\text { team), years }\end{array}$} \\
\hline Mean (s.d.) & $4.3(4.6)$ \\
\hline Median & 3.0 \\
\hline \multicolumn{2}{|l|}{ Time working in mental health services, years } \\
\hline Mean (s.d.) & $11.5(8.8)$ \\
\hline Median & 8.9 \\
\hline
\end{tabular}

CAMHS, child and adolescent mental health service; $\mathrm{CMHT}$, community mental health team; CRT, crisis resolution team; MHCOP, mental healthcare of older people; PICU, psychiatric intensive care unit.

a. The identifying number had been removed from 213 questionnaires, preventing us identifying the originating service; data from these are included in Tables 1 to 4 , but could not be included in the multilevel analyses (Table 5).

b. Ethnic group was initially measured with UK census categories: these were aggregated to form groups large enough for analysis.

of the sample. Staff on the national pay scales that reflect substantial managerial responsibilities (NHS Agenda for Change pay scales Band 7) and consultant psychiatrists were classified as senior: $12 \%$ met these criteria. Mean tenure in current service was 4.3 years and mean total service in mental healthcare was just under 12 years.

\section{Levels of morale by service type and profession}

Tables 2 and 3 summarise levels of morale categorised by service type and by profession for three indicators frequently used in previous research: emotional exhaustion and personal accomplishment measured on the Maslach Burnout Inventory, and whether the GHQ caseness threshold was reached. All other measures are shown in the online supplement to this paper (Tables DS1-4). Mean scores for burnout were below the standard high burnout threshold for most groups. ${ }^{8}$ Exceptions for emotional exhaustion were acute general wards, with a mean just above the burnout threshold and $49 \%$ of staff reaching this level, and CMHTs with a mean almost 3 points above the threshold and $60 \%$ reaching the threshold. Among professions, the mean for nurses and occupational therapists just reached the high burnout threshold, and social workers had the highest mean, 2 points above the threshold. No group reached high burnout thresholds on cynicism or lack of personal accomplishment.

For other measures, most service types and professions had mean scores above 3.0 on the depression-enthusiasm and anxiety-contentment scales, indicating inclination towards contentment and enthusiasm (online Tables DS1, DS3). Exceptions just below this threshold for anxiety-contentment were CMHT staff and social workers. The proportion of staff reaching caseness levels on the GHQ ranged from $22 \%$ of older adult ward staff to $39 \%$ of CMHT staff. Staff were reasonably satisfied with most aspects of work, with means well above the 3.0 level indicating neutrality (online Tables DS2, DS4). The exception was satisfaction with pay - only psychiatrists and psychologists were satisfied overall. Scores for satisfaction with colleagues were especially high. Job involvement did not vary significantly level by service type (Table DS2), but more by profession (Table DS4), with psychiatrists and service managers reporting the highest and nurses and social workers the lowest job involvement. The overall mean was 2.52 and means for all groups fell below 3.0: most participants did not agree strongly with items identifying work as central to their lives.

\section{Interrelationship of morale indicators and principal components analysis}

All the main morale indicators were highly significantly intercorrelated (online Table DS5), although the size of the correlations ranged from weak to fairly strong, with many in the medium range. Table 4 and online Fig. DS1 show results of a principal components analysis, exploring whether this large number of morale variables could be captured by a smaller number of components. With an eigenvalue threshold of 1.0 for retention of components and following varimax rotation, two components emerged. The first accounted for $43.2 \%$ of the variance, with loadings of more than 0.5 for all variables except personal accomplishment and job involvement. Loadings exceeded 0.7 for emotional exhaustion, GHQ-12 and the two job-related wellbeing variables. Thus, this component appeared to reflect emotional strain and/or distress and is subsequently referred to as the emotional strain component. The second component accounted for $19.5 \%$ of the variance: job involvement and personal accomplishment had the largest loadings, with substantial relationships also for intrinsic satisfaction and depression-enthusiasm, but not for other variables. This seemed to reflect how far staff members are engaged with and derive satisfaction from doing their work and is subsequently referred to as the positive engagement component. For further analyses, these components were scaled to the standard normal distribution so that mean differences reported below are measured in standard deviations.

\section{Multiply adjusted analyses}

Table 5 summarises and online Table DS6 shows in full the associations between emotional strain, positive engagement and 

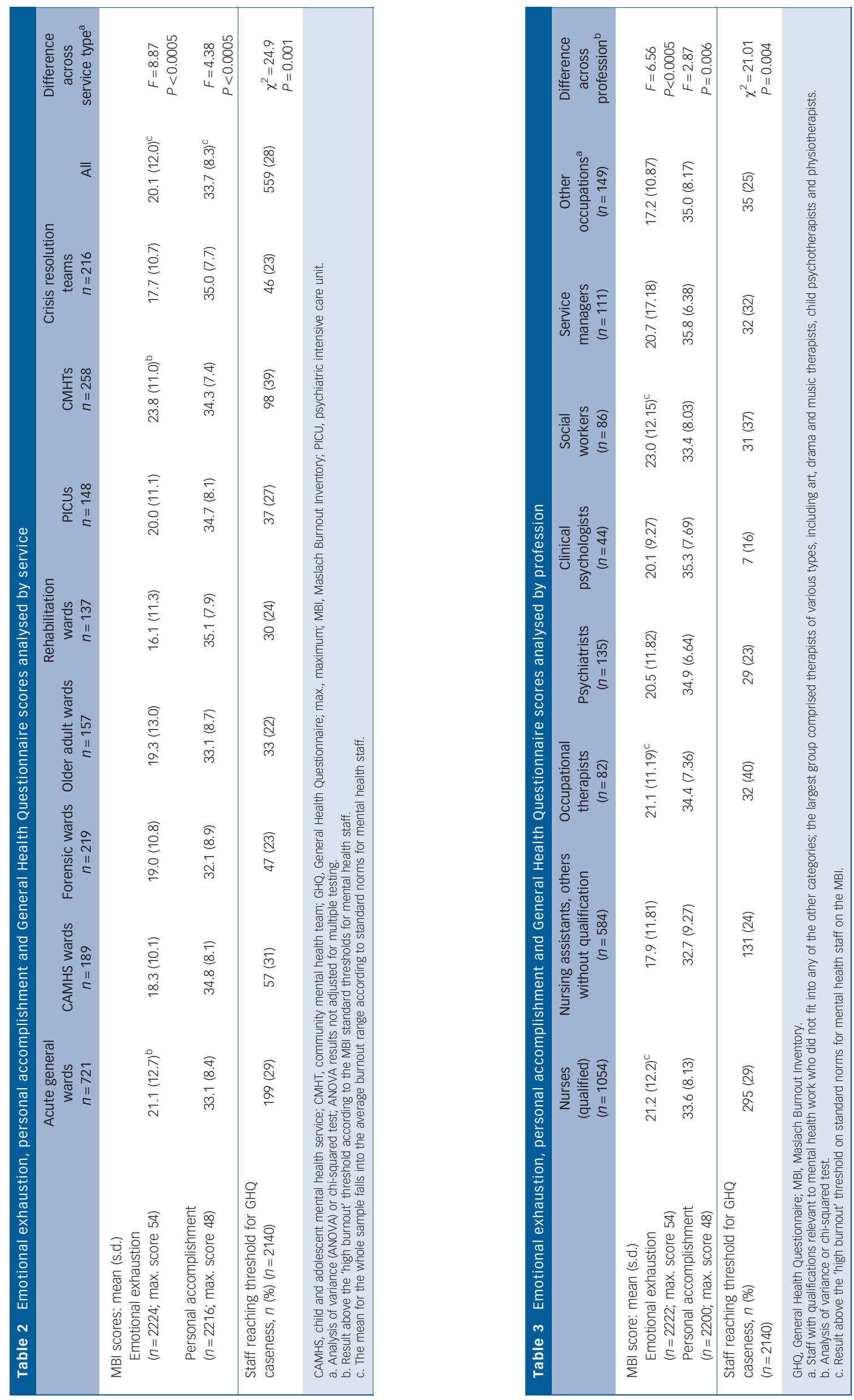
Table 4 Components obtained from morale indicators

with principal components analysis with varimax rotation

\begin{tabular}{|lcc|}
\hline Component loadings & $\begin{array}{c}\text { Component 1 } \\
\text { Emotional } \\
\text { strain }\end{array}$ & $\begin{array}{c}\text { Component 2 } \\
\text { Positive } \\
\text { engagement }\end{array}$ \\
Emotional exhaustion & & \\
Anxiety-contentment & 0.88 & -0.03 \\
GHQ score (log transformed) & -0.80 & 0.24 \\
Depression-enthusiasm & 0.80 & 0.24 \\
Cynicism & -0.79 & 0.40 \\
Intrinsic satisfaction & 0.65 & -0.03 \\
Personal accomplishment & -0.58 & 0.51 \\
Job involvement & -0.21 & 0.64 \\
\hline Variance, \% & 0.02 & 0.80 \\
Cumulative \% of variance & 43.2 & 19.5 \\
GHQ, General Health Questionnaire. & 43.2 & 62.7 \\
\hline
\end{tabular}

service type and profession, derived from multilevel regression analyses and multiply adjusted for demographic and other job-related variables. The proportion of variance at the service rather than individual level was estimated as 3.9\% for emotional strain and $4.3 \%$ for positive engagement. We initially also included healthcare trust as a higher level, but omitted it in the final analysis as the variance at trust level did not reach $1 \%$ for either component.

\section{Variables associated with emotional strain}

Emotional strain varied substantially by service type, with CAMHS, PICU, older people's, forensic and rehabilitation wards and CRTs all having significantly lower adjusted levels than acute general wards $(P<0.05)$ and CMHTs having higher levels. The largest adjusted effect was for rehabilitation wards, 0.41 s.d. below acute general wards. Variations by profession were less marked: the only significant differences were for staff without professional qualifications and for the other occupations group, 0.2 s.d. and 0.21 s.d. respectively below nurses. Other differences (online Table DS6) were less strain among older staff, married or cohabiting staff and temporary staff. Emotional strain tended to be higher among staff with longer tenure in their current service and those with longer total service in mental healthcare.

\section{Variables associated with positive engagement}

Positive engagement did not vary significantly by service type in these adjusted analyses. It was significantly associated with profession, with psychiatrists having a mean score 0.31 s.d. and service managers 0.40 s.d. above nurses (the reference group) (see Table 5). Another strong association was with ethnic group (Table DS6), with staff from both Black and Asian groups having adjusted means for positive engagement around a third of a standard deviation above the White groups $(0.32$ s.d. and 0.37 s.d. respectively). Those with longer total service in mental healthcare and those who had worked in their current service for more than a year had significantly lower positive engagement.

\section{Levels of demand, control and support}

There were highly significant differences between service types in demand and control variables (online Tables DS7 and DS8), with CMHT staff scoring higher than the rest on both demands and control. Rehabilitation ward, CAMHS and CRT staff also reported relatively high levels of autonomy in their work. Rehabilitation ward, PICU and CRT staff were at the lowest end of the range for demands, and forensic ward, older adult ward and PICU staff for control. Means for support from colleagues and managers

Table 5 Adjusted associations between morale components and service type and profession

\begin{tabular}{|c|c|c|c|c|c|c|c|c|}
\hline & \multicolumn{4}{|c|}{ Emotional strain component ${ }^{a}$} & \multicolumn{4}{|c|}{ Positive engagement component ${ }^{\text {b }}$} \\
\hline & \multicolumn{2}{|c|}{$\begin{array}{l}\text { Adjusted for demographic and } \\
\text { occupational characteristics }\end{array}$} & \multicolumn{2}{|c|}{$\begin{array}{l}\text { Additionally adjusted for job } \\
\text { demands, support, control }\end{array}$} & \multicolumn{2}{|c|}{$\begin{array}{l}\text { Adjusted for demographic and } \\
\text { occupational characteristics }\end{array}$} & \multicolumn{2}{|c|}{$\begin{array}{l}\text { Additionally adjusted for job } \\
\text { demands, support, control }\end{array}$} \\
\hline & Coefficient $(95 \% \mathrm{Cl})$ & $P$ & Coefficient $(95 \% \mathrm{Cl})$ & $P$ & Coefficient $(95 \% \mathrm{Cl})$ & $P$ & Coefficient $(95 \% \mathrm{Cl})$ & $P$ \\
\hline \multicolumn{9}{|l|}{ Service type } \\
\hline General acute & Reference & & & & & & & \\
\hline PICU & $-0.02(-0.19$ to 0.15$)$ & 0.85 & $0.19(0.06 \text { to } 0.33)^{\star \star}$ & 0.005 & $0.09(-0.12$ to 0.31$)$ & 0.34 & $0.11(-0.08$ to 0.29$)$ & 0.25 \\
\hline CAMHS & $-0.28(-0.44 \text { to }-0.12)^{\star \star *}$ & $<0.001$ & $-0.03(-0.15$ to 0.09$)$ & 0.64 & $0.18(-0.02$ to 0.38$)$ & 0.07 & $0.14(-0.03$ to 0.31$)$ & 0.11 \\
\hline Forensic & $-0.21(-0.36 \text { to }-0.06)^{\star *}$ & 0.005 & $-0.11(-0.24 \text { to } 0.00)^{*}$ & 0.05 & $-0.05(-0.23$ to 0.24$)$ & 0.56 & $-0.04(-0.20$ to 0.12$)$ & 0.62 \\
\hline Rehabilitation & $-0.41(-0.58 \text { to }-0.23)^{* * *}$ & $<0.001$ & $-0.09(-0.23$ to 0.05$)$ & 0.22 & $0.04(-0.17$ to 0.25$)$ & 0.71 & $-0.06(-0.25$ to 0.13$)$ & 0.54 \\
\hline Older adults & $-0.25(-0.42 \text { to }-0.08)^{* *}$ & 0.003 & $-0.12(-0.25$ to 0.01$)$ & 0.08 & $0.01(-0.20$ to 0.22$)$ & 0.92 & $-0.03(-0.21$ to 0.15$)$ & 0.73 \\
\hline $\mathrm{CMHT}$ & $0.20(0.05 \text { to } 0.35)^{\star * *}$ & 0.008 & $0.22(0.10 \text { to } 0.34)^{\star \star *}$ & $<0.001$ & $0.14(-0.03$ to 0.32$)$ & 0.11 & $-0.09(-0.25$ to 0.06$)$ & 0.25 \\
\hline Crisis team & $-0.32(-0.48 \text { to }-0.17)^{* * *}$ & $<0.001$ & $-0.01(-0.14$ to 0.11$)$ & 0.85 & $0.15(-0.03$ to 0.33$)$ & 0.10 & $0.09(-0.07$ to 0.25$)$ & 0.25 \\
\hline \multicolumn{9}{|l|}{ Occupation } \\
\hline \multicolumn{9}{|l|}{ Qualified nurses } \\
\hline staff & $-0.20(-0.31 \text { to }-0.08)^{\star * *}$ & 0.001 & 0.09 (0.00 to 0.18$)$ & 0.05 & $-0.10(-0.20$ to 0.02$)$ & 0.09 & $0.03(-0.07$ to 0.14$)$ & 0.53 \\
\hline $\begin{array}{l}\text { Occupational } \\
\text { therapists }\end{array}$ & $-0.02(-0.25$ to -0.21$)$ & \multicolumn{7}{|c|}{ Occupational } \\
\hline Psychiatrists & $0.08(-0.10$ to 0.27$)$ & 0.37 & $0.16(0.01 \text { to } 0.31)^{*}$ & 0.03 & $0.31(0.13 \text { to } 0.50)^{* * *}$ & 0.001 & $0.19(0.02 \text { to } 0.36)^{*}$ & 0.03 \\
\hline Clinical psychologists & $-0.11(-0.47$ to 0.23$)$ & 0.50 & $0.10(-0.17$ to 0.38$)$ & 0.47 & $0.06(-0.30$ to 0.42$)$ & 0.74 & $-0.16(-0.49$ to 0.17$)$ & 0.33 \\
\hline Social workers & $0.12(-0.12$ to 0.36$)$ & 0.32 & $-0.01(-0.20$ to 0.18$)$ & 0.91 & $-0.13(-0.37$ to 0.10$)$ & 0.27 & $0.07(-0.29$ to 0.14$)$ & 0.51 \\
\hline $\begin{array}{l}\text { Ward managers/ } \\
\text { team leaders }\end{array}$ & $0.08(-0.18$ to 0.35$)$ & 0.54 & $0.08(-0.15$ to 0.30$)$ & 0.49 & $0.40(0.15 \text { to } 0.65)^{* *}$ & 0.002 & $0.27(0.04 \text { to } 0.50)^{*}$ & 0.02 \\
\hline Other occupations & $-0.21(-0.39 \text { to }-0.02)^{*}$ & 0.03 & $0.09(-0.06$ to 0.23$)$ & 0.26 & $0.17(-0.01$ to 0.36$)$ & 0.07 & $0.09(-0.09$ to 0.26$)$ & 0.34 \\
\hline $\begin{array}{l}\text { CAMHS, child and adolesc } \\
\text { a. Negative scores indicate } \\
\text { b. Positive scores indicate } \\
{ }^{*} P<0.05 \text {, }{ }^{* *} P<0.01,{ }^{* * *} P\end{array}$ & $\begin{array}{l}\text { nental health service; } \mathrm{CMH} \\
\text { er levels of emotional strai } \\
\text { er levels of positive engage } \\
\text { D01. }\end{array}$ & $\begin{array}{l}\text { in the refe } \\
\text { t than the }\end{array}$ & $\begin{array}{l}\text { ference group. } \\
\text { e reference group. }\end{array}$ & & intensive care unit. & & & \\
\hline
\end{tabular}


varied less by service type and profession, although differences still reached statistical significance.

Demands and control varied still more widely by profession. Social workers and service managers reported the greatest demands and staff without professional qualifications the least, whereas the latter group also scored lowest for autonomy. Clinical psychologists reported levels of autonomy more than half a standard deviation above all other groups. Support varied less between professions than demands and control, with no significant difference for support from colleagues.

\section{Models including demand-control-support variables}

Table 5 shows the effects on associations between emotional strain, positive engagement and service type and profession of adding the demand, support and control variables; online Table DS9 shows in full the results of multilevel analyses including these variables and demographic and occupational characteristics. Emotional strain had highly significant associations with job demands, control and support from both managers and colleagues. The relationship with demands was especially large: one point greater job demands (on a five-point scale) were associated with half a standard deviation greater emotional strain. Some of the associations between emotional strain and service type or profession were no longer significant following adjustment for demands, control and support, including those with not having a professional qualification and with working on CAMHS, rehabilitation and older adult wards or in a CRT, and associations with length of service variables were attenuated. However, the association between greater emotional strain and working in a CMHT was unchanged.

All the Karasek model variables were also associated with positive engagement, but in the reverse direction for high job demands, which were associated with greater positive engagement. The association with control was especially strong, with 1 point higher score for control associated with a 0.38 s.d. increase in positive engagement. Adding demand, support and control to the model made little difference to the associations previously described with professions and demographic groups, indicating that perceived job characteristics do not explain these differences.

\section{Discussion}

The overall pattern of morale found in the mental health workforce was fairly encouraging. Staff tended to be satisfied with work and very satisfied with their colleagues, and they reported low levels of cynicism and good personal accomplishment. Where they were burnt out, as in most previous mental health workforce investigations this tended to take the form of high emotional exhaustion and the numbers reaching the threshold for caseness on the GHQ-12 were also substantial. That mental health work should have a high emotional impact is unsurprising, but a better understanding of this finding, its antecedents, its effect on patients and any effective means of alleviating psychological strain is nonetheless desirable.

There were considerable variations between service types. Acute general ward staff had mean emotional exhaustion scores just above the threshold for burnout, which is a matter for concern as these wards are numerous and have a key role in the mental health system. We compared these findings with levels reported in a previous systematic review; ${ }^{5}$ compared both with the mixed in-patient ward samples and with the acute ward samples in this review, emotional exhaustion in our study was at the higher end of the range. However, many previous studies had small samples and low response rates, so more confidence may be placed in our findings. Less explicably, we also found emotional exhaustion around 3 points higher than in the one previous large multicentre investigation of acute in-patient ward staff morale. ${ }^{23}$ Potential sources for this difference include a slightly higher response rate in our study, a mixed professional sample and the period of around 4 years that elapsed between the earlier study and our data collection. A small prospective cohort study of mental health staff morale showed relatively stable burnout over 2 years of follow-up; ${ }^{24}$ nonetheless, it may be that differences between our study and others reflect a tendency for overall workforce morale to fluctuate over time, especially at times of considerable change in the NHS.

Little has previously been published on variations between in-patient ward types. ${ }^{5}$ Morale indicators tended to be more positive on specialist wards, rehabilitation wards showing a particularly exemplary pattern of high personal accomplishment and low emotional exhaustion.

Turning to the community staff, our findings confirm a previous observation from a London study of good crisis resolution team staff morale despite the potential stresses of working with an acutely ill group in community settings. ${ }^{25}$ These staff rated support from colleagues very highly, suggesting a potential positive effect of the team approach implemented in CRTs. However, morale in CMHTs gives cause for concern. Despite good satisfaction, $60 \%$ of team members reached the burnout threshold on emotional exhaustion and 39\% were GHQ stressed 'cases'. These findings echo studies from the 1990s reporting high levels of burnout among CMHT staff, ${ }^{26}$ yet burnout in the investigations of the past decade has tended to be lower. ${ }^{27,28}$ Thus, in our study burnout seems to have reverted to levels that caused substantial concern about the teams' sustainability in the 1990s when this form of care was relatively new. $^{29}$

\section{Relationships between morale indicators}

Most correlations between the commonly used morale indicators were moderate, suggesting constructs that are partially independent of one another. However, two principal components captured $62 \%$ of the variation in the indicators, one that appeared to reflect emotional strain, the other positive engagement with work. This structure is in keeping with the recent theory (based on a range of occupational samples) that work-related well-being has two distinct underlying higher-order dimensions - negative states of burnout and positive engagement with work. ${ }^{30}$ Future research on the mental health workforce should ensure good coverage of these two dimensions.

\section{Explanatory value of the demand-support-control model}

As in many other occupational samples, ${ }^{15}$ the explanatory value of Karasek's demand-support-control model was confirmed. As elsewhere, high perceived demands were strongly associated with negative emotional states, and the extension of Karasek's theory that proposes an association between good job satisfaction and engagement and high job demands, high control and high support levels was also supported. Autonomy in carrying out job roles emerged as a key factor in staff well-being, strongly associated with both low emotional strain and high positive engagement. Support from colleagues and managers was also confirmed as associated with both components, but more modestly than the other Karasek variables. This suggests that interventions intended to reduce job demands or increase autonomy may be more likely to improve morale than strategies designed to enhance support. 
A further aim was to explore how far variations in demands, control and support might account for differences between service types and between professions. These variables had substantial explanatory value for variations in emotional strain: several of the initially significant variations between service types and professional and demographic groups in emotional strain were no longer significant with the Karasek variables in the model. Thus, for example, the lower emotional strain reported by rehabilitation ward and CRT staff can be accounted for by the finding that staff in these services report both substantially lower levels of job demands and greater control (Table DS7) than acute general ward staff. Higher levels of emotional strain in CMHTs, however, persisted unchanged when the Karasek variables were added to the model, suggesting that explanations need to be sought in terms of other aspects of their culture and working environments. Addition of the Karasek variables to the model for positive engagement had less influence on relationships with other variables, suggesting a need for alternative explanations of its variations. For example, the striking relationship between greater positive engagement and non-White ethnic groups did not appear related to differences in demand, support and control variables.

\section{Limitations and strengths of the study}

Strengths of our study include its size, which substantially exceeds any other investigation of the mental health workforce in the national and international literature, ${ }^{4,5}$ both in numbers participating and in geographical reach and coverage of different professions and subspecialties. The response rate is respectable, and we included a range of morale indicators, allowing comparison both with previous mental health investigations and with other samples in occupational psychology.

Limitations include the possibility of systematic differences between non-responders and responders, and we had no formal test of representativeness of the workforce as a whole. There were also wide differences in response rates per ward, with outliers at $22 \%$ and $100 \%$; thus, scores for some wards with low response rates might have been particularly unrepresentative. Despite excellent numbers overall, some groups within the sample are small. The cross-sectional nature of the study is also a significant limitation, especially in examination of the demand-supportcontrol model where causality cannot be established; for example, we cannot ascertain whether those with high work demands develop high levels of emotional strain, or whether the emotionally exhausted perceive work demands as high.

\section{Implications for research and service development}

Our study suggests several questions for further investigation. The interrelationship of morale indicators, the extent to which they are distinct and their potential reducibility to a smaller number of main dimensions bears further exploration using more sophisticated psychometric techniques within both this and other data-sets. Other candidate explanatory variables for variations in morale include organisational context, negative events, built environment, patient population and staff personality attributes. Prospective examination of the relationship between explanatory variables and morale indicators is also desirable. Links between staff morale and patient well-being and outcomes also remain poorly understood.

Our study suggests a need to focus on CMHT staff, and, to a lesser extent, those on acute general wards in further research and development of interventions. Our findings do not adequately explain the high levels of emotional strain in CMHTs - further quantitative and qualitative work on their antecedents, including an analysis of the many organisational changes experienced or anticipated by CMHT staff in the NHS, might help arrive at such an understanding, underpinning the development of interventions.

Although not all differences between groups can be accounted for by them, the Karasek model variables (demand, control/ autonomy and support) have substantial associations with both morale components, making the model a potential basis for developing interventions to raise morale. Mutual and managerial support tends currently to be the basis for interventions to improve mental health workforce morale and this is supported, but the effects for support are smaller than those for demands and autonomy. Designing interventions to reduce job demands is a challenge in the current climate of austerity in the NHS. ${ }^{31}$ Nonetheless, initiatives such as the Productive Wards programme, ${ }^{32}$ involving redesign of working environments and practices aimed at increasing staff time available for direct patient care and reducing other demands, may have some potential to reduce emotional strain. The substantial relationship between autonomy and both emotional strain and positive engagement suggests that this relatively neglected factor might be an appropriate focus for interventions, examining in detail the organisation of jobs and teams to identify ways in which autonomy might be increased, especially in groups of staff reporting low levels of this factor.

\section{Sonia Johnson, DM, David P. J. Osborn, PhD, Mental Health Sciences Unit, University College London; Ricardo Araya, PhD, School of Social and Community Medicine, Academic Unit of Psychiatry, University of Bristol; Elizabeth Wearn, BSc Medicine, Academic Unit of Psychiatry, University of Bristol; Elizabeth Wearn, BSC,
Mental Health Sciences Unit, University College London; Moli Paul, PhD, University of Warwick, Warwick Medical School, Coventry; Mai Stafford, PhD, Medical Research Council Unit for Lifelong Health and Ageing, London; Nigel Wellman, MSC, Thames Valley University; Fiona Nolan, PhD, Subdepartment of Clinical Health Psychology, University College London; Helen Killaspy, PhD, Brynmor Lloyd-Evans, PhD, Mental Health Sciences Unit, University College London; Emma Anderson, MSC, School of Social and Community Medicine, Academic Unit of Psychiatry, University of Bristol; Stephen J. Wood, PhD, School of Management, University of Leicester,} Leicester, UK

Correspondence: Professor Sonia Johnson, Mental Health Sciences Unit, University College London, Charles Bell House, 67-73 Riding House Street, London W1W 7EY, UK. Email: s.johnson@ucl.ac.uk

First received 4 Jul 2011, final revision 4 Apr 2012, accepted 30 Apr 2012

\section{Funding}

This project was funded by the National Institute for Health Services and Delivery Research Programme (project number/08/1604/142).

\section{Acknowledgements}

We wish to acknowledge the contribution of the other members of the In-patient Staff Morale Study research team, and are also very grateful for extensive support received from the North and South London, South-west, East of England and Heart of England hubs of the Mental Health Research Network, and for the helpfulness of staff in the 136 participating services. The views and opinions expressed in this paper are those of the authors and do not necessarily reflect those of the HS\&DR programme, NIHR, NHS or the Department of Health.

\section{References}

1 Reid Y, Johnson S, Morant N, Kuipers E, Szmukler G, Thornicroft G, et al. Explanations for stress and satisfaction in mental health professionals: a qualitative study. Soc Psychiatry Psychiatr Epidemiol 1999; 34: 301-8.

2 Department of Health. NHS Health and Wellbeing: Final Report. Department of Health, 2009 (http://www.nhshealthandwellbeing.org/FinalReport.html).

3 Tansella M, Thornicroft G. Implementation science: understanding the translation of evidence into practice. Br J Psychiatry 2009; 195: 283-5.

4 Paris M, Hoge MA. Burnout in the mental health workforce: a review. J Behav Health Serv Res 2010; 37: 519-28. 
5 Richards DA, Bee P, Barkham M, Gilbody SM, Cahill J, Glanville J. The prevalence of nursing staff stress on adult acute psychiatric in-patient wards - a systematic review. Soc Psychiatry Psychiatr Epidemiol 2006; 41: 34-43.

6 Reininghaus $\mathrm{U}$, Priebe S. Assessing morale in community mental health professionals: a pooled analysis of data from four European countries. Soc Psychiatry Psychiatr Epidemiol 2007; 42: 237-43.

7 Lasalvia A, Bonetto C, Bertani M, Bissoli S, Cristofalo D, Marella G. Influence of perceived organisational factors on job burnout: survey of community mental health staff. Br J Psychiatry 2009; 195: 537-44.

8 Maslach $\mathrm{C}$, Jackson SE. The measurement of experienced burnout. J Occup Behav 1981; 2: 99-113.

9 Warr $\mathrm{P}$. The measurement of well-being and other aspects of mental health J Occup Psychol 1990; 63: 193-210.

10 Kersley B, Alpin C, Forth J. Inside the Workplace: First Findings From the 2004 Workplace Employment Relations Survey (WERS 2004). Economic and Social Research Council, 2005.

11 Healthcare Commission. National Health Service Staff Survey. Healthcare Commission, 2006

12 Goldberg D, Williams P. The User's Guide to the General Health Questionnaire. nferNelson, 1988.

13 Lodahl TM, Kejner M. The definition and measurement of job involvement. J Appl Psychol 1965; 49: 24-33.

14 Tummers GER, Janssen PPM, Landeweerd A, Houkes I. A comparative study of work characteristics and reactions between general and mental health nurses: a multi-sample analysis. J Adv Nurs 2001; 36: 151-62.

15 Karasek RA. Job demands, job decision latitude, and mental strain: implications for job redesign. Admin Sci Q 1979; 24: 285-308.

16 Johansson G, Johnson JV, Hall EM. Smoking and sedentary behavior as related to work organization. Soc Sci Med 1991; 32: 837-46.

17 Wood S, Stride C, Threapleton K, Wearn E, Nolan F, Osborn D, et al. Demands, control, supportive relationships and well-being amongst British mental health workers. Soc Psychiatry Psychiatr Epidemiol 2011; 10: 1055-68.

18 De Jonge J, Kompier MAJ. A critical examination of the demand-controlsupport model from a work psychological perspective. Int J Stress Manag 1997; 4: 235-58
19 Haynes CE, Wall TD, Bolden RI, Stride C. Measures of perceived work characteristics for health services research: test of a measurement model and normative data. Br J Health Psychol 1999; 4: 257-75.

20 Snijderst, Bosker R. Multilevel Analysis: An Introduction to Basic and Advanced Multilevel Modelling. Sage, 1999.

21 White IR, Royston $\mathrm{P}$, Wood AM. Multiple imputation using chained equations: issues and guidance for practice. Stat Med 2011; 30: 377-99.

22 Royston P. Multiple imputation of missing values: update. Stata J 2005; 5: 188-201.

23 Bowers L, Allan T, Simpson A, Jones J, Whittington R. Morale is high in acute inpatient psychiatry. Soc Psychiatry Psychiatr Epidemiol 2009; 44: 39-46.

24 Prosser D, Johnson S, Kuipers E, Dunn G, Szmukler G, Reid Y, et al. Mental health, 'burnout' and job satisfaction in a longitudinal study of mental health staff. Soc Psychiatry Psychiatr Epidemiol 1999; 34: 295-300.

25 Nelson T, Johnson S, Bebbington P. Satisfaction and burnout among staff of crisis resolution, assertive outreach and community mental health teams. Soc Psychiatry Psychiatr Epidemiol 2009; 44: 541-9.

26 Prosser D, Johnson S, Kuipers E, Szmukler G, Bebbington P, Thornicroft G. Mental health, 'burnout' and job satisfaction among hospital and communitybased mental health staff. Br J Psychiatry 1996; 169: 334-7.

27 Priebe S, Fakhoury WKH, Hoffmann K, Powell RA. Morale and job perception of community mental health professionals in Berlin and London. SOC Psychiatry Psychiatr Epidemiol 2005; 40: 223-32.

28 Billings J, Johnson S, Bebbington P, Greaves A, Priebe S, Muijen M, et al. Assertive outreach teams in London: staff experiences and perceptions: PanLondon Assertive Outreach Study, Part 2. Br J Psychiatry 2003; 183: 139-47.

29 Wykes T, Stevens W, Everitt B. Stress in community care teams: will it affect the sustainability of community care? Soc Psychiatry Psychiatr Epidemiol 1997; 32: 398-407.

30 Schaufeli WB, Bakker AB. Job demands, job resources and their relationship with engagement and burnout: a multicentre study. J Organ Behav 2004; 25: 293-315.

31 Holloway F. 'Gentlemen, there is no money, therefore we must think' mental health services in hard times. Psychiatrist 2011; 35: 81-3.

32 Wilson G. Implementation of releasing time to care - the productive ward J Nurs Manag 2009; 17: 647-54. 